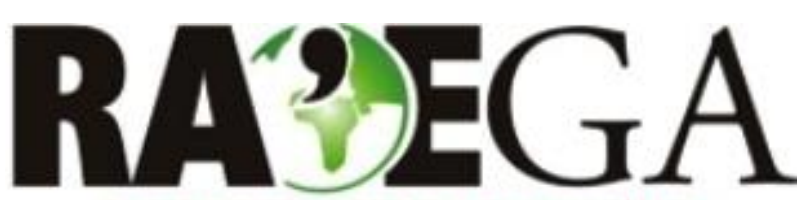

O ESPACCO GEOGRÁFICO EM ANÁLISE

\title{
PERSPECTIVAS DOS INSTRUMENTOS DEMOCRÁTICOS DE PLANEJAMENTO E GESTÃO DO TERRITÓRIO URBANO: AS FORMAS DE PARTICIPAÇÃO DA SOCIEDADE
}

\section{PERSPECTIVES OF DEMOCRATIC INSTRUMENTS PLANNING OF URBAN TERRITORY PLANNING AND MANAGEMENT: FORMS OF SOCIETAL PARTICIPATION}

\author{
Ideni Terezinha Antonello ${ }^{1}$
}

\section{RESUMO}

O objetivo central deste artigo é realizar uma reflexão sobre as perspectivas apresentadas pelos atuais instrumentos de planejamento e gestão urbanos, tendo como marco a Lei n.o 10.257/2001, denominada de Estatuto da Cidade. Com a aprovação desta lei, foram instituídas as bases legais para a aplicação dos instrumentos democráticos de planejamento e gestão do território urbano, mediante a orientação de formulação de planos com a probabilidade de uma efetiva participação popular. Diante disso, serão apresentadas e discutidas as diferentes formas de participação da sociedade no planejamento do território, apoiando-se na proposta de Raymond (2009) sobre os níveis de envolvimento da sociedade nesse processo. Com o intuito de discorrer acerca das perspectivas desses instrumentos, será trabalhada a experiência concreta de aplicação de um instrumento, o orçamento participativo, adotando como exemplo o município de Porto Alegre, Rio Grande do Sul/ Brasil.

PALAVRAS-CHAVE: Participação Popular, Níveis de envolvimento da sociedade, Lei n.o 10.257/2001.

\section{ABSTRACT}

This work aims mainly to reflect on the perspectives presented by the current instruments of urban planning and management, considering as a landmark the Law No. 10.257/2001 - named City Statute. With the approval of this law, the legal basis for the application of instruments of urban territory planning and management were established, through the guidance of formulation of plans with the prospect of an effective popular participation. Considering this, it will be presented and discussed different forms of societal participation in planning the territory, with support of Raymond's proposal (2009) on the levels of social involvement in this process. In order to show the potential of these tools, it will be analyzed the concrete experience of applying an instrument, namely Participatory Budgeting, taking as an example the city of Porto Alegre, state of Rio Grande do Sul, Brazil.

KEY-WORDS: Popular Participation, Levels of social involvement, Law No. 10.257/200

\footnotetext{
${ }^{1}$ Universidade Estadual de Londrina, UEL, Londrina/PR, e-mail: antonello.uel@gmail.com
} 


\section{ANTONELLO,I.T. \\ PERSPECTIVAS DOS INSTRUMENTOS DEMOCRÁTICOS DE PLANEJAMENTO E GESTÃO DO TERRITÓRIO URBANO: AS FORMAS DE PARTICIPAÇÃO DA SOCIEDADE}

\section{INTRODUÇÃO}

O escopo central desta análise é fazer uma discussão sobre as perspectivas dos instrumentos democráticos de planejamento e gestão do território urbano. Contudo, para adentrar no foco dessa reflexão, torna-se fundamental tecer uma análise da Lei n.으 10.257/2001, denominada de Estatuto da Cidade (ESTATUTO..., 2001). A referida lei constitui um marco para a política de desenvolvimento urbano, principalmente por trazer em seus pressupostos uma redefinição dos tradicionais planos diretores municipais, com vistas a instituir as bases legais para a aplicação dos instrumentos democráticos de planejamento e gestão do território urbano, mediante orientação sobre a formulação de planos diretores pautados na efetiva participação popular, bem como por reforçar as prerrogativas da gestão democrática.

Todavia, é necessário remeter essa análise ao processo de democratização e descentralização do poder do Estado brasileiro, ocorrido no período pós-ditatorial. Para tanto, retoma-se um ponto central no processo federativo nacional que tem como baliza a Constituição de 1988 (BRASIL, 1988). Mediante esse processo de democratização e descentralização do poder, é estabelecida uma nova relação entre os entes subnacionais, principalmente no que diz respeito à autonomia delegada aos municípios, já que estes passam a receber transferências de recursos federais e ganham autonomia para gerir suas finanças e seu patrimônio, levando-os a assumir atribuições no campo das políticas públicas.

Nesse contexto, é relevante destacar que a Constituição de 1988 criou as bases legais para a participação social na organização das cidades, pois as experiências de orçamento participativo frutificam-se após 1988 . Contudo a prática da participação social remonta à década de 1970, sendo consideradas precursoras as gestões de Lajes, em Santa Catariana, Boa Esperança, no Espírito Santo, e Piracicaba, em São Paulo. Ao desenvolver um estudo voltado para os novos arranjos participativos, tendo como um dos casos analisados o Brasil, Santos e
Avritzer (2003, p.20) defendem que a "Constituição foi capaz de incorporar novos elementos culturais, surgidos ao nível da sociedade, na institucionalidade emergente abrindo espaço para prática da democracia participativa".

Considera-se que práticas participativas, como o orçamento participativo, podem desencadear mudanças na cultura política por parte dos cidadãos e dos governantes, no momento em que se efetiva uma corresponsabilização entre gestão e sociedade. Tais práticas implicam novas formas de governo, mais transparentes e democráticas, não vinculadas aos limites de uma democracia representativa, mas direcionadas a trilharem o caminho para a consolidação da democracia participativa mediante o "[...] empoderamento (empowerment) das comunidades locais no processo decisório sobre políticas públicas" (SOUZA, 2004, p.27). No caso brasileiro, esse processo é permeado pela combinação entre a democracia representativa e a democracia participativa, na tentativa de "reinventar a emancipação social" (SANTOS; AVRITZER, 2003, p.12).

A Constituição de 1988 proporcionou o avanço de práticas participativas que estão inseridas em uma sociedade heterônoma. Por conseguinte, não se pode falar em uma democracia participativa total, mas apenas em uma complementaridade entre esta e a democracia representativa, ou seja, entre a escala nacional e a local, pois é nesta escala que os atores sociais (empoderamento) conseguem fortalecer e consolidar mecanismos participativos e de controle social da gestão governamental, na busca da "emancipação social", concretizando alternativas ao modelo hegemônico de poder, o que Santos e Avritzer (2003) denominam de práticas contra-hegemônicas. Nas palavras dos autores, na "[...] teoria contra-hegemónica da democracia: os actores que implantaram as experiências de democracia participativa colocaram em questão uma identidade que lhes fora atribuída externamente por um Estado colonial ou por um Estado autoritário e 


\section{ANTONELLO,I.T. \\ PERSPECTIVAS DOS INSTRUMENTOS DEMOCRÁTICOS DE PLANEJAMENTO E GESTÃO DO TERRITÓRIO URBANO: AS FORMAS DE PARTICIPAÇÃO DA SOCIEDADE}

discriminatório. [...] implica questionar uma gramática societária e estatal de exclusão e propor, em alternativa, uma outra mais inclusiva" (SANTOS; AVRITZER,2003, p.14).

Observa-se, assim, que a Constituição de 1988 criou o alicerce para o desenvolvimento de práticas participativas, como é o caso do orçamento participativo de Porto Alegre, objeto deste estudo, considerado um exemplo de exercício de participação cidadã que amplia a possibilidade de atuação de forma deliberativa e não restrita a dispositivos participativos. A esse respeito, faz-se necessário ressaltar o fato de que os mecanismos deliberativos proporcionam aos atores sociais a possibilidade de tomarem decisões de forma a interferir na ação da gestão pública voltada à produção do espaço urbano, o que significa que o resultado da participação de forma deliberativa se expressa na vida cotidiana da população, envolvendo a experiência pessoal e coletiva. Desse modo, tal participação expressa uma alternativa ao poder hegemônico, visto que pode se constituir em um pressuposto do arcabouço de práticas contra-hegemônicas.

Cabe salientar, ainda, que a Constituição de 1988, ao mesmo tempo em que foi o prelúdio do avanço de práticas contra-hegemônicas, reduziu toda a luta pela reforma urbana em dois artigos (182 e 183). Contudo, esse fato não silenciou as vozes que lutavam por uma reforma urbana; ao contrário, propiciou uma mobilização social em prol de uma legislação mais forte em escala federal, com objetivo de obter uma política urbana consistente. Assim, em 1990 foi

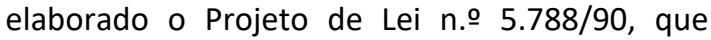
tramitou até 2001 no Congresso e originou a Lei n. 0 10.257, de 10 de julho de 2001, denominada de Estatuto da Cidade. Dessa forma, o Estatuto da Cidade é fruto da atuação dos movimentos sociais.

Apesar de o Estatuto da Cidade ser passível de críticas, sobretudo por não atacar diretamente a propriedade privada urbana, mas defender a função social dessa propriedade, o que, para muitos, não constitui mudança na essência da lógica capitalista da produção do espaço urbano, é considerado uma base institucional e legal inovadora, como defende Maricato: "Conquistamos muitas vitórias institucionais, como dois capítulos na Constituição de 1988 e a elaboração do Estatuto da Cidade, uma lei que o mundo inteiro admirou" (2012, p.1). Desse embate teórico sobre o significado do Estatuto da Cidade para a concretização de uma reforma urbana, chama atenção, na presente discussão, o seu arcabouço legal, que tem a prerrogativa de potencializar o direto de a sociedade atuar diretamente na gestão pública, alicerçando-se na "utopia experimental". Nesta análise, entende-se que a efetivação do "direito a cidade" pode ocorrer mediante a consolidação de práticas participativas de planejamento e gestão do território urbano, que podem criar as bases necessárias para atacar o modelo de planejamento e gestão urbanos tradicionais pautados em uma visão físico-territorial comanda pela racionalidade técnico-científica.

Tal modelo de planejamento tem como pressuposto um processo de decisão hierarquizado e centralizado no Estado via seus representantes legítimos: os planificadores. Assim sendo, os instrumentos de planejamento e gestão urbanos de cunho democrático presentes no Estatuto podem romper essa prática tradicional de planejamento, ao entender que "[...] toute planification doit être basée sur la mobilisation sociale élargie des acteurs. La planification doit alors engendrer un processus collectif de prise en main grâce au dialogue et à l'échange entre les acteurs" (DOUAY, 2013, p.53).

Porém, sabe-se que uma lei não tem o poder de concretizar a utopia coletiva do direito à cidade na sua totalidade, principalmente em uma sociedade heterônoma. Apesar disso, a lei é a base para frutificar formas contrahegemônicas, já que "La consultation des habitants est favorable à la démocratie, car elle permet la participation à la vie de la cité" (CHARBONNEAU, 2012, p.2). Assim, pondera-se que o Estatuto da Cidade representa um avanço na trajetória de uma prática de planejamento e gestão participativos do espaço urbano, ao instituir as diretrizes e os instrumentos para a 


\section{PERSPECTIVAS DOS INSTRUMENTOS DEMOCRÁTICOS DE PLANEJAMENTO E GESTÃO DO TERRITÓRIO URBANO: AS FORMAS DE PARTICIPAÇÃO DA SOCIEDADE}

efetivação dessa participação, possibilitando atingir o objetivo da função social da cidade e da propriedade urbana. O Estatuto proporciona, em especial, o respaldo jurídico para planejamento e gestão democráticos das cidades, destacando-se, nesse sentido, o orçamento participativo.

Nesse contexto, o objetivo central deste artigo consiste em refletir sobre as potencialidades dos instrumentos presentes no Estatuto da Cidade no que se refere ao planejamento e à gestão democráticos do território urbano, tendo como foco de análise o orçamento participativo. Com 0 intuito de analisar as perspectivas apresentadas por este instrumento para a gestão urbana participativa, será trabalhada a experiência concreta da aplicação do orçamento participativo, tomandose como exemplo o município de Porto Alegre, Rio Grande do Sul.

O presente artigo tem, assim, dois focos de análise que se complementam, estando, dessa forma, estruturado em dois eixos centrais. 0 primeiro volta-se para uma apreciação dos instrumentos de planejamento e gestão democráticos presentes no Estatuto da Cidade, com o fito de refletir sobre as prerrogativas do Estatuto em relação às possibilidades de fomentar o envolvimento da população na produção do espaço urbano. Tendo isso em vista, serão apresentadas e discutidas as diferentes formas de participação da sociedade no planejamento do território, tendo como apoio a proposta de Raymond (2009) sobre os níveis de envolvimento da sociedade nesse processo. $O$ segundo eixo, por sua vez, remete à análise da aplicação do orçamento participativo em Porto Alegre, com o escopo de apreender o significado que a cristalização da gestão urbana pautada em princípios participativos pode desempenhar para o avanço de uma democracia participativa, bem como identificar as formas de envolvimento da sociedade na gestão local, explorando o seu potencial contra-hegemônico para a ampliação da emancipação social.

\section{MATERIAIS E MÉTODOS}

Elucida-se que 0 procedimento metodológico que embasou esta análise consistiu, fundamentalmente, em um arcabouço teórico sobre a temática trabalhada e na utilização de dados estatísticos secundários, oriundos tanto de fontes de base estatística quanto de estudos sobre o orçamento participativo de Porto Alegre. 0 escopo de eleger uma experiência concreta de aplicação deste instrumento de gestão urbana encontra-se na tentativa de apreender o significado e o potencial da participação da sociedade nas domadas de decisão no processo de planejamento e gestão urbanos. A partir disso, será possível perceber a imbricação entre as formas de participação e os níveis de envolvimento da sociedade na prática participativa, bem como avaliar o potencial dos instrumentos democráticos de planejamento e gestão urbanos.

\section{RESULTADOS E DISCUSSÃO}

\subsection{OS INSTRUMENTOS DEMOCRÁTICOS DE PLANEJAMENTO E GESTÃO DO TERRITÓRIO URBANO: AS FORMAS DE PARTICIPAÇÃO DA SOCIEDADE}

Para apreender as bases de participação popular que podem ser desenvolvidas mediante as prerrogativas presentes no Estatuto da Cidade, cabe trazer para o foco desta análise o Estatuto, o qual, de forma geral, está estruturado em quatro partes: as diretrizes gerais do Estatuto, que são as metas a serem atendidas e que envolvem todas as esferas do poder público (municipal, estadual e federal); a Gestão Democrática nas Cidades; o Plano Diretor, realçando seu papel como instrumento básico da política de desenvolvimento e de expansão urbana; e os instrumentos previstos para alcançar o princípio de função social da propriedade.

Entretanto, antes de iniciar a análise dos instrumentos de gestão democrática, é importante ressaltar a criação do Ministério das Cidades (órgão do Poder Executivo Federal), em 2003, que representa a base de apoio federal para colocar em prática os princípios previstos no 


\section{ANTONELLO,I.T. \\ PERSPECTIVAS DOS INSTRUMENTOS DEMOCRÁTICOS DE PLANEJAMENTO E GESTÃO DO TERRITÓRIO URBANO: AS FORMAS DE PARTICIPAÇÃO DA SOCIEDADE}

Estatuto da Cidade, como, por exemplo, a construção de uma política urbana pautada em um modelo participativo. Dessa forma, foram criados fóruns nacionais de discussão sobre essa temática, que se desdobraram na I Conferência Nacional das Cidades (2003), resultando na eleição e na composição do Conselho das Cidades - ConCidade - Quanto à Gestão Democrática nas Cidades, esta envolve diretamente a construção de planos diretores participativos e do orçamento participativo, ou seja, apresenta uma expectativa de implantar um planejamento e uma gestão urbanos participativos. O Estatuto da Cidade incorpora o pressuposto de uma gestão democrática, ao introduzi-lo como diretriz da política urbana, previsto no inciso II do Art. 2으, bem como prevê, no Art. 43, os mecanismos para a sua aplicação, ao estabelecer a realização de debates, audiências e consultas públicas; conferências sobre assuntos de interesse urbano, nos níveis nacional, estadual e municipal; e órgãos colegiados de política urbana, nos níveis nacional, estadual e municipal (Lei Federal n.은 10.257 de 10/07/2001).

As audiências e consultas públicas são mecanismos basilares para garantir a gestão democrática da cidade, porque asseguram ao cidadão o princípio constitucional do direito à informação e à participação. Assim sendo, essas consultas devem ser promovidas e amplamente divulgadas pelo poder público. Com base nesse preceito, as audiências públicas são obrigatórias no Legislativo Municipal para aprovar os instrumentos de planejamento e gestão, como, por exemplo, o Plano Diretor e o Orçamento Anual.

No caso da elaboração do Plano Diretor, para atingir o objetivo central de um planejamento participativo, é necessário criar as condições para a efetiva participação popular em todas as suas fases, isto é, desde a configuração do Plano Diretor até o controle popular na gestão dos Poderes Executivo e Legislativo municipais. Esses mecanismos se encontram previstos no $\S$ 4o do Art. 40 do Estatuto da Cidade.

Deste artigo destaca-se a importância das audiências e consultas públicas, pois têm como finalidade informar, esclarecer e fornecer dados e documentos sobre o projeto do plano, de forma que seu escopo central é transmitir as informações necessárias à população para que esta possa se posicionar em relação à proposta de planejamento municipal. Nesse sentido, podese mencionar a defesa de Charbonneau (2002, 2012, 2014) sobre "la pédagogie urbaine", que corresponde à necessidade de criar uma dinâmica coletiva na cidade, pautada na tentativa de eliminar a imposição técnica vinculada ao poder governamental e construir um conhecimento comum da cidade para atingir um projeto coletivo.

Esse projeto coletivo pode ser desenhado por meio das audiências públicas, em que todos os cidadãos têm o direito de manifestar suas opiniões, apresentarem propostas e proporem soluções e alternativas. Trata-se, assim, de um direto e dever de participar do processo de elaboração do Plano Diretor municipal, uma vez que esse plano consiste na principal política de desenvolvimento urbano do município, bem como da gestão mediante o orçamento participativo. Dessa forma, pode-se desenvolver "la pédagogie urbaine", colocando em prática uma metodologia que vise compartilhar conhecimento entre os responsáveis técnicos e a população. Para isso, é necessária a produção de documentos de fácil compreensão para favorecer um debate bem estruturado e pautado na informação acessível a todos, uma vez que a essência da pedagogia urbana é "[...] faire comprendre absolument ce qui est en jeu pour nourrir des débats, en recueillir les fruits, alimenter le projet, lui donner son ancrage, sa pertinence" (CHARBONNEAU, 2002, p.1).

A esse respeito, ressalta-se o orçamento participativo, que baliza a gestão orçamentária participativa, podendo se tornar um instrumento que fomente a prática de uma pedagogia urbana, pois a prerrogativa de uma gestão orçamentária participativa assenta-se no fundamento de o cidadão exercer o direito de fiscalizar as finanças públicas e, principalmente, o direito de participar na elaboração e na execução do orçamento 


\section{ANTONELLO,I.T. \\ PERSPECTIVAS DOS INSTRUMENTOS DEMOCRÁTICOS DE PLANEJAMENTO E GESTÃO DO TERRITÓRIO URBANO: AS FORMAS DE PARTICIPAÇÃO DA SOCIEDADE}

municipal, o que representa a possibilidade de a população participar nas definições das prioridades de investimentos para o município. De forma sintética, é possível afirmar que “[...] o orçamento participativo permite a participação dos cidadãos não eleitos na concepção e/ou na alocação dos recursos públicos" (SINTOMER; HERBERG; RÖCKE, 2010, p.49). Esse instrumento está previsto no Estatuto da Cidade nos Art. 4으 e Art. 44.

Todavia, existe uma discrepância entre o que está previsto em lei e sua efetivação, já que o desafio democrático vinculado à prática participativa para a construção coletiva da cidade perpassa pelo grau de envolvimento da população com o projeto comum. Nesse sentido, a participação da sociedade pode ocorrer de diferentes formas, as quais serão a expressão do papel que desempenhará a sociedade civil no planejamento e na gestão coletiva do território urbano.

$\mathrm{Na}$ perspectiva de apreender os fatores e as condições que determinam a forma de participação da sociedade, Raymond (2009) propôs uma escala dos graus de envolvimento do público com o intuito de identificar os diferentes papéis atribuídos à sociedade. A proposta desse autor, reproduzida na Figura 1, é crucial ao se analisar o potencial dos instrumentos de planejamento e gestão urbanos para a materialização de uma democracia participativa.

Observa-se que o grau de envolvimento do público varia conforme os mecanismos de participação, os quais, segundo Raymond (2009, p.18), têm relação direta com a escala, pois o envolvimento do cidadão decresce à medida que se afasta do nível local para o regional e nacional. Assim sendo, quanto maior for o espaço que o projeto de intervenção no território abrange, mais tênue será o grau de envolvimento. Portanto, a escala local permite um processo decisório que incumbe a população de maior poder na elaboração e aplicação de um projeto no território. Na base dessa proposta, encontrase a legítima participação, isto é, a autogestão (l'auto-gestion), que corresponde ao envolvimento direto dos atores sociais na vida do território.

No caso da gestão participativa (la gestion participative), o processo decisório ocorre por meio da gestão compartilhada, no sentido de que os atores sociais participam juntamente com as autoridades administrativas e políticas. Nessa forma de gestão, embora a sociedade civil possua o poder de participar das decisões, não atua na implementação do projeto proposto, mas no monitoramento da sua execução. Pode-se inferir que essa prática participativa proporcione um avanço em relação ao envolvimento da sociedade no planejamento e na gestão do território, pois se pauta na prerrogativa da participação com poder de decisão.

Dentre as demais formas de participação da sociedade na gestão coletiva do território, pode-se citar a coconstrução na decisão pública (la co-construction de la décision publique), já que possibilita certo grau de participação, ainda que destinada apenas a determinados membros da sociedade. 


\title{
ANTONELLO,I.T. \\ PERSPECTIVAS DOS INSTRUMENTOS DEMOCRÁTICOS DE PLANEJAMENTO E GESTÃO DO TERRITÓRIO URBANO: AS FORMAS DE PARTICIPAÇÃO DA SOCIEDADE
}

\author{
Dégrés \\ d'implication \\ du public
}

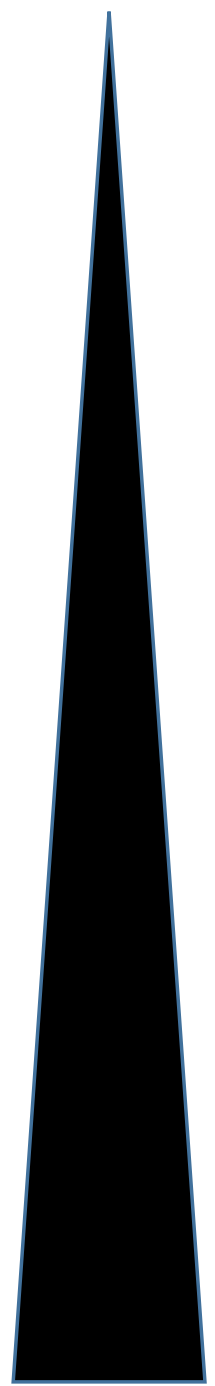

La sensibilisation du public consiste à diffuser, à partir d'une source institutionnelle ou patentée, une idée générale et abstraite. La sensibilisation du public ne concerne pas um territoire en particulier mais un príncipe d'action. L'idé est que, dans ce cas, les príncipes qui guident les orientations de l'aménegement du territoire ne soient pas remis en cause par la soociété civile.

L'inforamtion vise à faire comprendre et partager par la société civile un diagnostic fait par d'autres ou une décision prise par une autorité administrative ou politique. Dans ce cas, la société civile est le réceptacle de l'information et aucun avis n'est attender en retour.

La consultation oú l'opinion de la société civile est recueillie sans que cet avis ne modifie nécessairement la decision prise.

La concertation où des acteurs de la société civile sont invites à la "préparation partiellement négociée d'une décision que sera prise par une autorité administrative ou politique".

La co-construction de la décision publique, quando certains membres de la société civile sont invités à élaborer um projet, dont la mise en œuvre et le suivi seront réalisés sous l'autorité d'acteurs administratifis ou politiques.

La gestion participative proprement dite oú des représentants de la société civile participent aux instances de décisions et de suivi du projet aux côtés de représentants des autorités administratifis ou politiques.

L'auto-gestion, où un ensemble de bénéficiaires d'un projet se voient confier la mise en œuvre d'un projet qu'ils ont contribué à definir, L'État ou le gouvernement local se contentat de vérifier a posteriori la validité juridique des mesures prises. Les partisans de cette forme la plus achevée de la participation et de la decentralization estiment qu'à ce stade l'implication des acteurs peut entraîner des changements profonds e durables. Cette forme de participation s'accompagnerait d'une reprise en main du devenir et de la vie du territoire par la société civile, celle-ci portant véritablement ses projets.

Dégrés

d'implication

du public

Fonte: Raymond (2009, p. 19)

Figura 01 - Dégrés d’implication du public

As demais formas não apresentam um grau de envolvimento forte da sociedade com o processo decisório, porque não criam mecanismos que elevem o poder de atuação dos atores sociais, tornando-se inócuas na perspectiva de uma gestão democrática do território. Apesar disso, essas formas de envolvimento, presentes no planejamento e na gestão do território, revestem-se de um discurso que exalta a importância da participação da sociedade, constituindo-se, essencialmente, em estratégias pertencentes ao jogo do poder. Consequentemente, essa "parceira" ou envolvimento figura como uma "ferramenta polivalente" nas mãos da administração pública e dos políticos, sendo personificada pela própria 


\section{ANTONELLO,I.T. \\ PERSPECTIVAS DOS INSTRUMENTOS DEMOCRÁTICOS DE PLANEJAMENTO E GESTÃO DO TERRITÓRIO URBANO: AS FORMAS DE PARTICIPAÇÃO DA SOCIEDADE}

sociedade civil como um fetiche que levará à sua participação (RAYMOND, 2009).

O que emerge da discussão acerca das diferentes formas que assume a participação social no planejamento e na gestão do território é a necessidade de pensar se essas formas realmente consistem em mecanismos que proporcionam as condições ao exercício de uma democracia participativa e se assumem um caráter contra-hegemônico que possa fomentar a "emancipação social" ou se, pelo contrário, são utilizadas como ferramentas de manobra para atender aos interesses da gestão administrativa e política. Essa preocupação é engendrada no momento em que, apesar de constar em lei federal, a gestão orçamentária participativa apresenta um caráter diferenciado no território nacional, uma vez que cabe ao poder municipal definir, mediante Lei Orgânica e outras leis municipais, as finanças públicas e as diretrizes do processo de participação popular como précondição para a aprovação do orçamento anual do respectivo município. Logo, a gestão orçamentária participativa ganha a especificidade da forma de sua aplicação em cada município brasileiro que utiliza o instrumento do orçamento participativo.

Tendo isso em vista, no item seguinte deste trabalho, realizar-se-á uma reflexão sobre as potencialidades e os limites das formas de participação no planejamento e na gestão urbanos. O foco dessa discussão consistirá na concretização do orçamento participativo de Porto Alegre.

\subsection{ORÇAMENTO PARTICIPATIVO DE PORTO ALEGRE - FORMAS DE ENVOLVIMENTO DA SOCIEDADE}

A gestão orçamentária participativa tem sido colocada em prática em diferentes municípios brasileiros. Dentre as experiências do orçamento participativo, ganha visibilidade a do Município de Porto Alegre, iniciada em 1989, pelo fato de ter criado raízes ao longo dos anos na sociedade da capital do estado do Rio Grande do Sul, localizado na Região Sul do Brasil.
Acredita-se que a consolidação dessa prática participativa em Porto Alegre advenha dos critérios implantados na sua realização, que garantiram transparência e credibilidade ao processo de gestão entre a sociedade e a gestão governamental. Esses critérios são expostos por Santos (1998, p.33):

(a) all citizens are entitled to participate, community organizations having no special status or prerogative in this regard; (b) participation is governed by a combination of direct and representative democracy rules and takes place through regularly functioning institutions whose internal rules are decided upon by the participants; c) investment resources are allocated acoording to an objective method based on a combination of "general criteria" - substantive criteria established by the participatory institutions to define priorities - and "technical criteria" - criteria of technical or economic viability as defined by the executive and federal, state, or city legal norms - that are up to the executive to implement.

Ao levar em consideração os critérios mencionados por Santos (1998), pode-se afirmar que a gestão orçamentária foi se fortificando e se tornando uma alternativa de inclusão da sociedade perante o poder hegemônico, o que ampliou, consequentemente, o potencial de uma democracia participativa, como aduzem Santos e Avritzer (2003). Contudo, é necessário analisar a dinâmica do orçamento participativo portoalegrense, para, com base nessas reflexões, reaver a proposta de Raymond (2009), na perspectiva de identificar o grau de envolvimento da sociedade no orçamento participativo e compreender o papel que essa prática participativa desempenha no que concerne a reinventar a democracia e ampliar a emancipação social.

Para iniciar a análise do orçamento participativo, é importante contextualizar a dimensão populacional do município de Porto 


\section{ANTONELLO,I.T. \\ PERSPECTIVAS DOS INSTRUMENTOS DEMOCRÁTICOS DE PLANEJAMENTO E GESTÃO DO TERRITÓRIO URBANO: AS FORMAS DE PARTICIPAÇÃO DA SOCIEDADE}

Alegre, que contava com 1.360 .590 habitantes, em 2000, e com 1.409.351 habitantes, em 2011 (IBGE, 2012). Tal questão ganha visibilidade, uma vez que uma das hipóteses deste artigo era que o universo populacional municipal tornaria inviável a gestão orçamentária. Porém, os dados sobre a participação da população no orçamento participativo porto-alegrense contrariam essa tese, conforme se pode constatar por meio da evolução do número de participantes.

Os dados revelam que, em seis anos de implementação, o orçamento participativo ganha adesão social, ao passar de 628 para 7.653 participantes (1990-1996), crescendo em ritmo constante até 2002, quando atinge o auge da participação, com 17.241 participantes. A partir desse ano, observa-se uma desaceleração na participação, de modo que, em 2006, havia 11.536 participantes, caracterizando uma redução significativa de 2003 a 2006 . Em relação à diminuição da participação nesse período, uma das hipóteses consiste no sentimento de incongruência entre a participação e a concretização das demandas prioritárias definidas no orçamento participativo, já que o município passou por uma crise financeira a partir de 2000, o que não possibilitou a execução das metas de investimentos estabelecidas no período (FEDOZZI, et al., 2013). Entretanto, a partir de 2007, essa participação voltou a crescer, chegando, em 2012, a 16.721 participantes no total das assembleias.

É possível observar, mediante o número de participantes nas assembleias, que a gestão democrática apresenta uma dinâmica consistente e demonstra um avanço na integração de participantes no orçamento público. Outro dado importante é o percentual do orçamento dedicado à decisão popular. Em Porto Alegre, nos anos de 1999 e 2000, cerca de $21 \%$ e $15 \%$ do total da despesa municipal foram decididos pelo orçamento participativo, respectivamente (SOUZA, 2000, 2006).

O orçamento participativo constitui-se em uma renovação na forma de elaborar e executar o orçamento municipal, introduzindo um elemento essencial à participação, pois, por seu intermédio, as decisões sobre a arrecadação e os gastos públicos não ficam a cargo apenas dos técnicos da burocracia estatal e governantes: o poder é redirecionado para a participação direta de pessoas, comunidades, associações de moradores, movimentos sociais e organizações da sociedade civil. Como defende Wampler (2008, p.69),

É um programa inovador, pois suas regras promovem justiça social ao assegurar mais recursos para áreas mais pobres, ao encorajar a participação através da distribuição de recursos para cada uma das regiões do município em função da mobilização dos membros das respectivas comunidades e ao estabelecer novos mecanismos de responsabilização que acabam desvendando e inviabilizando procedimentos orçamentários obscuros.

A materialização da gestão orçamentária participativa em Porto Alegre foi organizada no espaço municipal via a criação de instâncias temáticas e assembleias por região do orçamento participativo. Primeiramente, o espaço foi divido em dezesseis regiões (atualmente, foi criada mais uma região - Região das Ilhas), e os critérios para sua delimitação foram geográficos, sociais e de organização comunitária. As instâncias temáticas correspondem: (a) à organização da cidade e ao desenvolvimento urbano; (b) à circulação e ao transporte; (c) à saúde e à assistência social; (d) à educação, à cultura e o lazer; e (e) ao desenvolvimento econômico e à tributação.

A divisão do município em unidades espaciais (regiões) para a elaboração da gestão participativa torna-se relevante, por levar em conta não apenas critérios especificamente técnicos, mas também a expressão de uma identidade social que se enraizou por meio do sentimento de pertencimento, dos laços comunitários e da organização do ativismo de bairro (SOUZA, 2006). Essa identidade socioterritorial desponta como base para a adesão dos atores sociais à proposta da gestão orçamentária participativa, pois possibilita a 


\section{PERSPECTIVAS DOS INSTRUMENTOS DEMOCRÁTICOS DE PLANEJAMENTO E GESTÃO DO TERRITÓRIO URBANO: AS FORMAS DE PARTICIPAÇÃO DA SOCIEDADE}

união em prol de um objetivo coletivo. Tal afirmativa pode ser corroborada ao se observar que a participação nas plenárias do orçamento participativo por regiões, segue a mesma evolução de participação que as assembleis gerais, enquanto que as plenárias temáticas apresentam uma participação ínfima em relação às supracitadas. Em 2009, por exemplo, a participação na instância regional foi de $49,8 \%$ e na regional juntamente com a temática foi de $45,1 \%$, enquanto que somente a temática teve uma adesão de 3,8\% dos participantes (FEDOZZI, 2007, 2009).

Essa dinâmica pode estar vinculada à questão territorial/regional, cujo foco são as demandas do espaço vivido pela sociedade, ao passo que as instâncias temáticas possuem um teor mais amplo, ligado às políticas públicas, de modo que não se consegue criar complementaridade entre as plenárias temáticas e as regionais. Sobressai-se desse contexto o fenômeno da desarticulação entre as demandas sociais setorizadas, que possuem suas respectivas instâncias participativas por meio dos Conselhos Municipais, e a elaboração do orçamento participativo. Segundo Fedozzi et al (2013, p.24), "Essa fragmentação e suas possíveis sobreposições de instâncias podem estar dificultando a melhoria qualitativa da democracia participativa praticada na cidade".

O formato do orçamento participativo, criado para possibilitar a participação da sociedade, é constituído de duas grandes rodadas de reuniões plenárias nas regiões e nas instâncias temáticas, sendo finalizado nas plenárias. As formas de participação direta dos atores sociais ocorrem em ambas as rodadas. A primeira tem o objetivo de apresentar as contas do plano de investimentos aprovado no ano anterior, com a finalidade de informar a população sobre as metas que foram cumpridas ou não e o que está em andamento. Elucida-se que, entre essas duas grandes rodadas, são efetivadas reuniões para o levantamento das principais carências da população, a fim de definir as obras prioritárias e, dessa forma, obter uma sistematização das propostas (BANCO MUNDIAL, 2008; FEDOZZI, 2007, 2009).

Na segunda rodada, os participantes de todas as instâncias de discussão realizadas debatem e apresentam as propostas sistematizadas sobre as prioridades para aquele ano, bem como elegem seus conselheiros, os quais terão o mandato para o orçamento participativo de um ano. Cabe salientar que, em 2007, foi alterado o regimento para permitir a reeleição sem limite de tempo para os conselheiros. Essa alteração não foi bem aceita pelos participantes, já que $51,1 \%$ são favoráveis à reeleição, mas com prazo limitado (FEDOZZI, et al, 2013, p.70).

O processo do orçamento participativo é colocado em marcha por um sistema de gestão desse orçamento, que é formada por esferas públicas não estatais - o Fórum de Delegados Regionais e Temáticos e o Conselho do Orçamento Participativo. Este último é composto de delegados e conselheiros escolhidos nas regiões e instâncias temáticas (totalizando 44 conselheiros titulares). Nas instâncias temáticas, são realizadas várias reuniões com os órgãos governamentais para a elaboração do orçamento municipal e do plano de investimentos. Após sua confecção, o plano é avaliado pelo Conselho do Orçamento Participativo. Nesse momento, iniciase o intenso processo de discussão e negociação entre os conselheiros, a comunidade e os órgãos governamentais. Conforme Santos e Avritzer (2005, p. 66) “ As assembleias regionais, as listas de acesso prévio a bens públicos e o conselho do orçamento participativo expressam uma dimensão que denominamos acima de procedimento participativo, um processo de participação ampliada envolvendo um amplo debate público sobre as regras da participação, da deliberação e da distribuição".

O resultado é a peça orçamentária obtida por meio do processo participativo, a qual será enviada ao executivo, pois o prefeito tem prerrogativa legal de conduzir a proposta orçamentária à Câmara Municipal para votação do legislativo. No caso de Porto Alegre, contudo, o poder de alterar o que foi decidido no coletivo 


\section{ANTONELLO,I.T. \\ PERSPECTIVAS DOS INSTRUMENTOS DEMOCRÁTICOS DE PLANEJAMENTO E GESTÃO DO TERRITÓRIO URBANO: AS FORMAS DE PARTICIPAÇÃO DA SOCIEDADE}

pelo prefeito é restringindo, já que “[...] uma maioria de dois terços dos conselheiros pode derrubar um veto do prefeito" (SOUZA, 2006, p.456).

Sobre a percepção dos participantes no que diz respeito à concretização da proposta coletiva, ou seja, ao resultado final da peça orçamentária, pode-se verificar uma tendência pessimista. Em 1995, 60,3\% dos participantes consideravam que "sempre e quase sempre" a população decide; já em 2009, esse percentual passa para 53,7\%. Chama atenção, ainda, a percepção em relação ao "sempre" decide, que passa de 33,0\%, em 1995, para 21,7\%, em 2009, e ao "nunca" decide, que passa de $0,6 \%$, em 1995, para 3,8\%, em 2009 (FEDOZZI, et al. 2013).

Apesar dos obstáculos enfrentados, pode-se afirmar que o formato desenvolvido para a efetivação da gestão participativa, em determinados períodos, ganha adesão, como em 2002, e, em outros, perde. Nesse sentido, tratase de uma construção que não se apresenta de forma estável, embora venha se consolidando com o passar do tempo. Essa consolidação pode ser fruto da união conquistada pela identidade territorial tecida ao longo do processo histórico da construção do espaço vivido, o qual, na maioria das vezes, é produto de contradições próprias do urbano, marcado pela segregação socioeconômica, que repele parte expressiva da população brasileira para as periferias das cidades, não sendo diferente na realidade portoalegrense.

A produção desigual do espaço urbano engendra a exclusão territorial, que impõe a seus moradores vivenciar as carências de equipamentos técnicos e sociais urbanos. Diante disso, faz-se necessário articular a atuação de uma gestão orçamentária democrática à perspectiva regional-territorial, a fim de apontar as problemáticas específicas de cada região (habitacionais, de saneamento ambiental, de mobilidade urbana, de saúde, entre outras), pois é a população que, ao produzir e vivenciar esse espaço, conhece empiricamente as prioridades locais. Como alerta Capel (2010), perante uma urbanização permeada de contradições socioterritoriais, é fundamental pensar na construção de uma cidade baseada no diálogo e na participação da sociedade.

Nesse sentido, ressalta-se novamente a regionalização do orçamento participativo de Porto Alegre, já que essa ganha relevância por permitir ultrapassar o espaço concebido e adentrar no espaço vivido/percebido. A esse respeito, conforme Koga e Nakano, "Constata-se que ainda há muitos invisíveis nesses territórios que precisam se tornar visíveis. Precisamos de novas cartografias, que nos permitam ver dimensões e complexidades socioterritoriais ocultas" (2005, p. 73), pois é no espaço vivido que afloram, com intensidade, as dimensões ocultas camufladas nos dados e nas estatísticas oficiais. Assim, a prática participativa pode produzir uma "nova cartografia", desenhada pelas mãos invisíveis que passam a se fazer presentes mediante a sua atuação como cidadão, principalmente tendo em vista que os participantes/atores do orçamento participativo de Porto Alegre apresentam o seguinte perfil:

É, portanto, possível identificar o representante típico das rodadas como pertencente aos segmentos pobres e organizados da população de Porto Alegre, tendo uma baixa renda familiar e pouco ou nenhuma educação formal. Os delegados e os conselheiros possuem uma renda maior e melhor nível de educação do que o participante típico das rodadas. Entretanto, mesmo os delegados e conselheiros possuem uma renda familiar inferior à renda média da cidade (MARQUETTI, 2002, p.6)

O perfil dos atores sociais que se mobilizam na prática da gestão orçamentária partilhada demonstra que esta pode constituir uma alternativa inclusiva que se materializa no espaço urbano de Porto Alegre, uma vez que "[...] o orçamento participativo tem oferecido uma inversão de prioridades: centros de saúde foram implantados em áreas pobres, o número de escolas e creches aumentou, as ruas foram asfaltadas, e a maioria das casas tem acesso ao 


\section{ANTONELLO,I.T. \\ PERSPECTIVAS DOS INSTRUMENTOS DEMOCRÁTICOS DE PLANEJAMENTO E GESTÃO DO TERRITÓRIO URBANO: AS FORMAS DE PARTICIPAÇÃO DA SOCIEDADE}

abastecimento de água e esgoto" (FERNÁNDEZ, 2010, p.45). Considera-se que as condições fomentadoras desses resultados se encontram na regionalização e nos critérios adotados na gestão orçamentária participativa (SANTOS, 1998), os quais se expressam em três formas de institucionalidade participativa:

Em primeiro lugar, assembleias regionais nas quais a participação é individual, aberta a todos os membros da comunidade e cujas regras de deliberação e de decisão são definidas pelos próprios participantes. Em segundo lugar, um princípio distributivo capaz de reverter desigualdades préexistentes em relação à distribuição de bens públicos. [...]. Em terceiro lugar, há um mecanismo de compatibilização entre o processo de participação e de deliberação e o poder público, processo esse que envolve, no caso de Porto Alegre, o funcionamento de um conselho capaz de deliberar sobre o orçamento e de negociar prioridades com a prefeitura local (SANTOS; AVRITZER, 2003, p. 20-21).

A experiência da gestão orçamentária participativa de Porto Alegre indica que as discussões e os debates com a população são o pressuposto central da elaboração das prioridades de investimento do orçamento municipal. Essa valorização social, que cria espaço para que as vozes dos atores sociais ganhem ressonância na atuação do poder executivo e legislativo municipal, fomenta o exercício da cidadania, pois, como afirma Souza (2000), a gestão orçamentária participativa de Porto Alegre extrapola o aspecto socioeconômico, tendo em vista o seu potencial "pedagógico" que pode contribuir para formação de uma consciência cidadã, tal como prevê Charbonneau (2002) ao defender "la pédagogie urbaine". Assim sendo, a gestão democrática porto-alegrense pode resultar no avanço da democracia participativa. Segundo Santos e Avritzer (2005, p. 66), "Temos, portanto, no caso do brasileiro, uma primeira forma bem-sucedida de combinação entre elementos da democracia representativa e da democracia participativa".

Logo, é preciso correlacionar o formato e a dinâmica do orçamento participativo à forma de envolvimento da sociedade na gestão do território urbano. Conforme a proposta de Raymond (2009), esse envolvimento se constitui em uma gestão participativa (la gestion participative), já que o processo decisório ocorre mediante uma gestão compartilhada entre os atores sociais, que não possuem o controle integral como na autogestão (l'auto-gestion), e o poder administrativo e político municipal. Nesse caso, entra em análise a questão do poder de decisão delegado à sociedade na proposta final do orçamento participativo, que, como salientado anteriormente, passa por uma tendência negativa na visão dos participantes.

Nessa forma de gestão compartilhada, a confiança na relação desenvolvida entre poder público (representantes da administração local), representantes dos participantes (delegados e conselheiros) e sociedade (participantes do orçamento participativo) torna-se fulcral ao processo participativo, definindo a expectativa de concretização das decisões tomadas nas instâncias participativas. Por conseguinte, a satisfação dos participantes no que diz respeito à transparência, ao acesso às informações e às prestações de contas realizadas pelos representantes da administração pública e dos participantes do orçamento participativo é um dos parâmetros para apreender a abrangência da qualidade do processo participativo.

Tal dinâmica pode ser vislumbrada por meio dos dados sobre a satisfação dos participantes do orçamento participativo em relação aos itens supracitados. Em 1995, 80\% dos participantes estavam satisfeitos com as informações prestadas no que se refere ao desempenho dos representantes da administração local, índice que caiu para 40,1\%, em 2009; já quanto ao desempenho dos representantes dos participantes, esse percentual passou de 50,7\%, em 1995, para 23,5\%, em 2009 (FEDOZZI, et al., 2013). Elucidase que o grau de insatisfação em relação aos 


\section{PERSPECTIVAS DOS INSTRUMENTOS DEMOCRÁTICOS DE PLANEJAMENTO E GESTÃO DO TERRITÓRIO URBANO: AS FORMAS DE PARTICIPAÇÃO DA SOCIEDADE}

representantes do poder local se diferencia entre os participantes que nunca assumiram a atividade de conselheiros e os que já a exerceram, ou seja, os que já possuem experiência na função de conselheiro exigem informações claras e detalhadas.

$\mathrm{Na}$ proposta de Raymond (2009), a gestão participativa encontra-se na base da pirâmide do grau de envolvimento da sociedade no planejamento e na gestão do território, o que indica o potencial dessa forma de participação, desde que não seja manipulada por outros interesses que não o coletivo. Nesse sentido, novamente vem à tona a importância da pedagogia urbana, uma vez que uma população bem informada e consciente de seus direitos não se torna alvo de retóricas e prédicas de dominação social.

Essa questão é crucial para pensar as perspectivas que o orçamento participativo lança na sociedade, pois, além de favorecer a participação direta da população na decisão das prioridades na implementação dos equipamentos urbanos no seu espaço, fomenta a conscientização de que todos produzem o espaço urbano, criando uma corresponsabilidade na gestão do território.

Observa-se que a visão dos participantes passa por um processo de mudança, conforme o tempo de atuação e permanência no orçamento participativo, pois aqueles com uma participação de oito anos ou mais (veteranos) têm um sentimento vinculado aos valores comunitários e democráticos maior/mais desenvolvido/mais aguçado que aqueles com menor tempo de presença no orçamento participativo, o que revela a importância da questão da identidade com o território em que vivem.

É visível a importância que assumem as demandas por equipamentos urbanos no território porto-alegrense, uma vez que essa razão variou entre $29,2 \%$ e $50,1 \%$ das respostas dos participantes/entrevistados - nesse caso, sobressai o tempo de participação, já que para os iniciantes $(50,1 \%)$ esta é a principal razão, a qual sofre uma redução conforme a experiência participativa (29,2\%). Nesse sentido, Fernández
(2010, p.31) defende que o potencial dos processos participativos se encontra no fato de que: "[...] costumam realizar-se de forma periódica, como os Orçamentos Participativos, o que permite aos cidadãos voltarem a participar, caso desejem, mas porque essa continuidade facilita a visualização do meio em que se vive e a influência que tem o processo participativo sobre ele de uma forma mais transparente".

O fato de a população poder observar a concretização das suas demandas fomenta a vontade de participar, bem como a percepção de que o envolvimento participativo não se traduz em mera miragem, mas se cristaliza no seu espaço vivido, vivificando uma "utopia experimental" e criando, consequentemente, o sentimento de identidade territorial, o que contribuiu para o avanço de uma democracia participativa ao fomentar a visão de cidadania. Essa visão fica evidente ao constatar que 54,2\% dentre as razões de participação para os veteranos vinculam-se à identidade e solidariedade. Além disso, se forem acrescentados os $11,9 \%$ do motivo da participação associado à democracia e aos direitos, chega-se à conclusão de que $66,1 \%$ das razões consistem na concepção de uma emancipação social que não se reduz a demandas de infraestruturas, mas faz jus à relevância que a gestão orçamentária adquire junto à população do município e, particularmente, demonstra o potencial desse instrumento para que se criem as possibilidades de participação de uma sociedade consciente e atuante na produção do seu espaço.

\section{CONSIDERAÇÕES FINAIS}

A aplicação dos instrumentos democráticos de planejamento e gestão no território urbano, principalmente sustentada pelas prerrogativas previstas no Estatuto da Cidade, é um caminho a ser trilhado, cujos obstáculos podem ser removidos por meio da conscientização da sociedade sobre o valor da sua participação. Tal luta deve estar pautada em uma participação deliberativa, e não apenas representativa, uma vez que, conforme propõe Raymond (2009), o envolvimento da sociedade 


\section{ANTONELLO,I.T. \\ PERSPECTIVAS DOS INSTRUMENTOS DEMOCRÁTICOS DE PLANEJAMENTO E GESTÃO DO TERRITÓRIO URBANO: AS FORMAS DE PARTICIPAÇÃO DA SOCIEDADE}

no planejamento do território tem de assumir uma forma de gestão participativa (la gestion participative) e, em determinadas escalas, colocar em prática a autogestão (l'auto-gestion).

Em relação ao orçamento participativo porto-alegrense, objeto de análise deste artigo, observa-se que o grau de envolvimento da sociedade influencia o metabolismo do tecido social de uma parte da população. Tal dinâmica se tornou possível mediante as formas de participação elaboradas e colocadas em prática, criando um processo de efetiva gestão participativa, por meio da gestão compartilhada entre o poder público local e a sociedade. Todavia, percebe-se que essa dinâmica é marcada por avanços e retrocessos.

Quanto aos retrocessos, considera-se importante introduzir mudanças no que diz respeito: a) ao planejamento participativo, que não ganhou a mesma dinâmica da gestão orçamentária, ao apresentar um plano diretor que diverge do pressuposto pela participação popular, bem como ao planejamento urbano, que se encontra independente do orçamento participativo, o que não possibilita uma visão de futuro integrada para o espaço urbano; b) à gestão orçamentária imediatista, vinculada a obras locais, sem que haja uma perspectiva de interconexão entre o planejamento e a gestão; c) à falta de conexão entre o orçamento participativo e os diversos conselhos municipais, já que estes deveriam convergir, ao se constituírem em mecanismos democráticos e possuírem interesses comuns; d) à reeleição, que deveria ser permitida sem limite de tempo para os conselheiros; e) à atenção concedida em relação à a percepção dos participantes acerca de se a população decide o que ocorrerá, pois está aumentando o percentual que considera que a população "nunca decide"; d) e ao processo de distanciamento entre os representantes e representados (administração pública e dos participantes). É necessário atentar a esses pontos levantados para não retroceder nos avanços obtidos ao longo dos anos de prática de uma gestão urbana compartilhada.
Já em relação aos avanços no orçamento participativo, ressalta-se, essencialmente, que sua dinâmica consiste em uma alternativa ao padrão dominante de gestão governamental, pois o orçamento participativo de Porto Alegre é um ponto luminoso que agrega a população do município em prol da luta para transformar seu espaço vivido, catalisando elementos fundantes de uma sociedade autônoma em comparação a antigas formas de articulação entre a sociedade e o sistema político. Além de fomentar um desenho de práticas democráticas que pode ferir o modelo hegemônico da democracia liberal e, assim, abrir espaço para formas de envolvimento da sociedade com o seu território, desenvolve uma visão cidadã que extrapola a luta por infraestruturas urbanas e atinge a essência de consciência coletiva mediante a emancipação social.

Nesse sentido, a ampliação da experiência porto-alegrense pode se converter na tese defendida por Santos e Avritzer (2003), de que a disseminação dessas alternativas de participação local pode vir a fortalecer a articulação contra-hegemônica em escala global, pois ultrapassar o local é primordial para ampliar a democracia participativa. Pode-se considerar que o Brasil está dando os primeiros passos nessa direção, que começou a ser trilhada com a Constituição de 1988, a qual lançou as balizas necessárias para o desenvolvimento de práticas participativas e se desdobrou no Estatuto da Cidade, no Ministério das Cidades, na Conferência Nacional das Cidades e no Conselho das Cidades. Para se ter uma noção da dimensão participativa no Brasil, basta observar a existência de mais 25 mil Conselhos Municipais (nos setores da educação, saúde, meio ambiente, entre outros) no território nacional. Entretanto, cabe uma análise cautelosa das formas de envolvimento da sociedade para não cair na retórica de que a participação da sociedade consiste na panaceia para as contradições socioterritoriais que marcam o espaço urbano nacional ou de que a participação social é sinônimo de ampliação da gestão democrática. 


\section{PERSPECTIVAS DOS INSTRUMENTOS DEMOCRÁTICOS DE PLANEJAMENTO E GESTÃO DO TERRITÓRIO URBANO: AS FORMAS DE PARTICIPAÇÃO DA SOCIEDADE}

No entanto, é possível pensar em uma ressignificação da prática participativa no país na perspectiva de avanços no procedimento democrático, com a finalidade de criar alternativas de participação que não sejam meras autorizações de governos à atuação dos atores sociais, mas que se transformem em um exercício coletivo de poder de ação perante a gestão, tal como o orçamento participativo de Porto Alegre, que se cristaliza em alternativa ao poder hegemônico. Percebe-se, assim, que o orçamento participativo não muda a democracia moderna, mas pode ser um mecanismo para "democratizar a democracia". Por conseguinte, é necessário explorar ao máximo os instrumentos de planejamento e gestão democráticos presentes na Constituição de 1988 e, principalmente, o Estatuto da Cidade, que é o sustentáculo legal da sociedade para exigir o direito de inclusão no espaço urbano, ou seja, para que se concretize o princípio central desta Lei o cumprimento da função social da propriedade.

Nesse sentido, é fundamental adentrar nas formas de participação da sociedade no planejamento e na gestão urbanos para descortinar a efetiva participação, ou seja, o grau de envolvimento da sociedade. Isso permitirá não subjugar o potencial da prática participativa ao "discurso da participação", pois esse discurso alimenta e nutre os interesses de determinados grupos políticos e econômicos que visam a uma cidadania inerte e calada perante a realidade do seu espaço vivido, cultuando uma democracia representativa, e não uma democracia participativa.

É necessário, assim, que a participação social se traduza em uma pedagogia urbana que possa fomentar a criticidade em um processo educacional que não se limite ao ato da participação, mas alcance uma pedagogia do espaço vivido que assuma o significado de emancipação social, contribuindo para ampliar a democracia participativa. Dessa forma, avançar no planejamento e na gestão do território urbano em prol do interesse coletivo proporcionará maior qualidade de vida nas cidades para a sociedade.

\section{REFERÊNCIAS}

BANCO MUNDIAL. Para um orçamento participativo mais inclusivo e efetivo em Porto Alegre. Relatório no 40144 - BR. Washington /EUA, 2008.

BRASIL. Constituição. Constituição da República Federativa do Brasil. RJ: Gráfica Auriverde, 1988.

CAPEL, H. Urbanización generalizada, derecho a la ciudad y derecho para la ciudad. In: XI COLOQUIO INTERNACIONAL DE GEOCRÍTICA. Buenos Aires, 2 - 7 de maio de 2010. Actas la planificación territorial y el urbanismo desde el diálogo y la participación. Buenos Aires: Universidad de Buenos Aires, 2010, p. 1-34. Disponível em http:www.filo.uba. Acesso em 10 de agosto de 2010.

CHARBONNEAU, Jean-Pierre. Dossier: À école de la ville. Revie I'Urbanisme, 2002.Disponível em www.revieunbanisme.fr . Acesso em 01 de maio de 2010.

" Les temps de la concertation. L'expérience du centre de Saint-Denis ", Métropolitiques, 2012. Disponível em http://www.metropolitiques.eu/Les-temps-de-laconcertation-L.html. Acesso em 30 de novembro de 2014 .

Exposer l'urbanisme (in extenso), 2014.

Disponível em http://www.urbanisme.fr/issue/report.php?code =32. Acesso em 27 de novembro de 2014.

DOUAY, Nicolas. La planification urbaine française: théories, normes juridiques et défis pour la pratique. L'information Géographique, Paris: Armand Colin, volume 77, no 3, p.45-70, 2013.

FEDOZZI, L. Observando o Orçamento participativo de Porto Alegre - análise histórica de dados: perfil social e associativo, avaliação e expectativas. Porto Alegre: Tomo, 2007.

ObservaPOA. Observando o OP de Porto

Alegre: perfil social e associativo, avaliação, formação de uma cultura política democrática e possíveis inovações. Porto Alegre, 2009.

FEDOZZI, L. et al. Orçamento participativo de Porto Alegre / Perfil, avaliação e percepções do público participante. Porto Alegre: Gráfica e Editora Hartmann, 2013. 


\section{ANTONELLO,I.T. \\ PERSPECTIVAS DOS INSTRUMENTOS DEMOCRÁTICOS DE PLANEJAMENTO E GESTÃO DO TERRITÓRIO URBANO: AS FORMAS DE PARTICIPAÇÃO DA SOCIEDADE}

FERNÁNDEZ, E.G. Novos instrumentos de participação: entre a participação e a deliberação. In: SILVA, E. M. da; CUNHA, E. S. M. (Orgs.). Experiências internacionais de participação. SP: Cortez. (Coleção Pensando a Democracia participativa, v.2), 2010, p.19-40.

LEI FEDERAL n 10.257 de 10/07/2001 (O Estatuto da Cidade). Diário Oficial da União, Seção I (Atos do Poder legislativo). Edição $\mathrm{n}^{\circ} 133$ de 11 /07/2001.

IBGE - Instituto Brasileiro de Geografia e Estatística. Censos Demográficos. Disponível em www.ibge.gov.br. Acesso em 10 de fevereiro de 2013.

KOGA, D; NAKANO K.Perspectivas Territoriais e Regionais para políticas públicas brasileiras. Cadernos Abong - Associação Brasileira de Organizações Não Governamentais, Brasília: Abong, p.68-74, 2005.

MARICATO, E. Nossas cidades estão ficando inviáveis. Desafios do Desenvolvimento: Revista de Informação e Debates do IPEA, Brasília: IPEA, ano 9, no 75, 2012. Disponível em:http://desafios.ipea.gov.br/index.php?option =com_content $\&$ view $=$ article $\& i d=2508$ : catid=28\&l temid=23. Acesso em 14 de maio de 2014.

MARQUETTI, A. O orçamento participativo como uma política redistributiva em Porto Alegre. I Encontro de Economia Gaúcha. Porto Alegre, $2002 . \quad$ Disponível em: www.fee.tche.br/sitefee/download/eeg/1/mesa_ 9_marquetti.pdf. Acesso em 20 de novembro de 2012.

RAYMOND, Richard. La "société civile» ce «nouvel» acteur de l'aménagement des territoires. L'information Géographique, Paris: Armand Colin, volume 73, no 2, p.10-29, 2009.

SANTOS, BOAVENTURA de Sousa. Participatory Budgeting in Porto Alegre: Toward a Redistributive Democracy. Politics Society, p.461510, $1998 . \quad$ Disponível em http://www.sagepublications.com. Acesso 20 de agosto de 2014.

SANTOS, BOAVENTURA de Sousa; AVRITZER, Leonardo. Introdução. In: SANTOS, BOAVENTURA de Sousa (Organizador). Democratizar a democracia. Os caminhos da democracia participativa. SP: Civilização Brasileira, 2005, p.38-82.

SANTOS, BOAVENTURA de Sousa; AVRITZER, Leonardo. Para ampliar o cânone democrático. Eurozine Review, 2003, p. 1-53. Disponível em http://www.eurozine.com/articles/article_200311-03-santos-pt.html\#footNoteNUM13. Acesso em 19 de agosto de 2014.

SOUZA, M. L de. Os orçamentos participativos e sua espacialidade: uma agenda de pesquisa. Terra Livre, SP, no 15, p.39-58, 2000.

- Mudar a cidade: uma introdução crítica ao planejamento e à gestão urbanos. 4a ed., RJ: Bertrand Brasil, 2006.

SOUZA, C. Governos locais e gestão de políticas sociais universais. São Paulo em Perspectiva, 18 (2), p.27-41, 2004.

SINTOMER, Y; HERBERG, C; RÖCKE, A. O Orçamento Participativo na Europa: potencialidades e desafios. In: SILVA, E. M. da; CUNHA, E. S. M.(Orgs.). Experiências internacionais de participação. SP: Cortez. (Coleção Pensando a Democracia participativa, v.2), 2010, p.41-66.

WAMPLER, Brian. A difusão do Orçamento Participativo brasileiro: "boas práticas" devem ser promovidas? Opinião Pública, Campinas, vol. 14, no 1, p.65-95, 2008. 